\title{
Feasibility of Tsunami Early Warning Systems for small volcanic islands
}

\author{
G. Bellotti ${ }^{1}$, M. Di Risio ${ }^{2}$, and P. De Girolamo ${ }^{2}$ \\ ${ }^{1}$ DSIC, University of Roma TRE, Rome, Italy \\ ${ }^{2}$ DISAT-LIAM, University of L'Aquila, DISAT-LIAM, Monteluco di Roio, Italy
}

Received: 17 June 2009 - Revised: 12 October 2009 - Accepted: 26 October 2009 - Published: 17 November 2009

\begin{abstract}
This paper investigates the feasibility of Tsunami Early Warning Systems for small volcanic islands focusing on warning of waves generated by landslides at the coast of the island itself. The critical concern is if there is enough time to spread the alarm once the system has recognized that a tsunami has been generated. We use the results of a large scale physical model experiment in order to estimate the time that tsunamis take to travel around the island inundating the coast. We discuss how and where it is convenient to place instruments for the measurement of the waves.
\end{abstract}

\section{Introduction}

Tsunami waves are mostly generated by earthquakes and landslides. In both cases the largest waves, and therefore the more destructive effects, are induced along the coastal regions in proximity of the tsunamigenic sources: these areas are attacked by the waves after a very short time since their generation. It is therefore clear that any warning system intended to launching warn for such hazards should be able to detect the tsunamis and to give the alarm very quickly. These systems are commonly referred to as Tsunami Early Warning Systems (TEWS).

One special case of application of these warning systems is volcanic islands prone to tsunami generation along the coast of the island itself. In these cases eruptions, crater collapses and landslides can generate tsunamis. The tsunamigenic source is located in proximity of the coast and therefore the time available for spreading the alarm is extremely short. Of course the tsunamis may be dangerous also for coastal regions far from the island (Tinti et al., 2003), and the warning system should be able of spreading the alarm also to the far

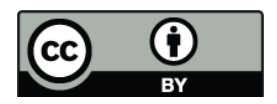

Correspondence to: G. Bellotti (bellotti@uniroma3.it) field regions; however this part of the problem is not tackled in this research, that focuses only on the protection of the coast of the island itself.

One interesting example of the conditions described above is the island of Stromboli, located in the South Tyrrhenian Sea (Italy), about 30 nautical miles from the coasts of Italy (Maramai et al., 2005). The volcano has been affected by many collapses and is persistently active ("Strombolian activity"). One of the most recent collapses (Tibaldi, 2001) generated a scar known as "Sciara del Fuoco" (hereinafter referred to as $\mathrm{SdF}$ ).

As documented by Maramai et al. (2005), five tsunamis attacked Stromboli between 1916 and 1988. More recently, the 30 December 2002 tsunamis were generated by landslides on the SdF; refer to Tinti et al. (2005) for detailed reconstruction of the events and to Tinti et al. (2006) for numerical computations of landslide and tsunami.

After the tsunami of 2002 a monitoring system, which is still operating, was installed at Stromboli by the Italian $\mathrm{Au}-$ thorities. The system concentrates on the tsunami hazard posed by the SdF (Tinti et al., 2008). It is composed of instruments that monitor instabilities of the subaerial flank of the volcano (Casagli et al., 2009) and one instrument that measures the water elevation in order to detect tsunamis. The former alert the population of the island if a landslide occurs; the latter confirms the hazard if a tsunami has been generated.

The idea of measuring both the source and the effect (the tsunami) follows the more modern approach for tsunami warning systems. Nowadays are available sophisticated and accurate systems for the monitoring of unstable subaerial flanks, that can predict the occurrence of landslides. However since not all the landslide/earthquakes are tsunamigenic, spreading alarms only on the basis of the measurement of the sources may lead to a large number of false alarms. This would make the system to appear not reliable to the population, and may lead people not to trust it when alarms are spread.

Published by Copernicus Publications on behalf of the European Geosciences Union. 
The waves monitoring system should be able above all of detecting if a tsunami has been triggered by the source. If tsunamis are detected the alarm is immediately spread to the population. The most critical point to be addressed when designing the TEWS is therefore what is the amount of time elapsed between the first detection of the tsunami and the arrival of the tsunami at the location(s) of the coast that the system is aimed at protecting.

Furthermore using the wave measurement system it is possible to predict the inundation level at the coastal points of interest, not only the occurrence of the inundation. This may be of the utmost importance, since would allow to assess in real time what are the areas to be evacuated, and what is the safe distance from the sea. This task is extremely difficult: given the small time available when the source is very close to the coast to protect, it is unfeasible to wait until the maximum height wave has been measured at the gauges to calculate the inundation level. The system would certainly be much more useful if a dynamic prediction of the inundation is given as the waves are measured (Bellotti et al., 2008). It is clear that flooding maps and evacuation plans should be worked out in advance, and that such a system may only give in real time the level of warning, given the measured height of the waves. Reasonably we can assume that when the maximum surface elevation value has been recorded at the wave gauges, the system is able of estimating the maximum inundation at the coastal points; the time elapsed between the measurement and the arrival of the largest wave is therefore another critical parameter to be considered during the design of the TEWS.

Another important issue is where to measure the waves. Is it convenient to place wave gauges directly along the coast (coastal gauges) or offshore?

Coastal wave gauges are the most obvious way of measuring tsunamis propagating along the coast. They can be located at protected points of the coastline, and direct data transfer to onshore receiving stations can be obtained using cables. However, care should be used when deploying cables, since the action of the waves may easily damage them. Furthermore, in the nearshore region the waves are measured in limited water depths, where the short waves, especially during storms, may hide to some extent the long tsunami waves. Beltrami and Di Risio (2009) have investigated how to detect long waves during a short waves storm and have concluded that the accuracy of the detection procedure deteriorates if short waves are to be filtered out, but the detection still retains its reliability.

Offshore gauges, such as pressure sensors, may be deployed at considerable water depths. The data transfer to onshore receiving stations can reasonably be obtained only using wireless connections. Since the water column naturally filters out the short waves effect, the tsunami detection algorithms can be applied without need of a low-pass filter and the system is therefore expected to be more effective (Beltrami, 2008).
In this paper we use new experimental data related to landslide-tsunamis propagating around a conical island, to provide the scientific community with results that may guide the design of a warning system. Only the hydraulic part of the problem will be considered. As discussed later in more detail the island reproduced in the laboratory, as well as the landslide used to generate the tsunamis, have many similarities with the island of Stromboli, if this is scaled down of 1000 times using the Froude scaling law. This would correspond to a scaling factor of 1000 for lengths and of $\sqrt{1000}$ for times. Important parameters, such as the slope and the diameter of the island, the shape and the volume of the landslide, can be seen as idealized model reproduction of the Stromboli tsunami of 2002. Of course our intent is not to reproduce exactly that case, but to use it as reference for producing results of more general validity.

This paper is organized as follows. The next section describes the physical model experiment. The following section describes the results and presents analysis useful for the present purposes. The final section discusses the results and gives some recommendation for the design/improvement of TEWS for small islands.

\section{Description of the physical model experiment}

The experiments have been described in detail by Di Risio et al. (2009a). They have been carried out in a large wave tank at the Research and Experimentation Laboratory for Coastal Defense (LIC) of the Technical University of Bari (Italy) in cooperation with the Environmental And Maritime Hydraulics Laboratory "Umberto Messina" (LIAM) of the University of L'Aquila. The wave tank is $30.00 \mathrm{~m}$ wide, $50.00 \mathrm{~m}$ long and $3.00 \mathrm{~m}$ deep. In this paper we focus on experimental tests for which water level into the tank has been set to about $0.75 \mathrm{~m}$, so that the radius of the undisturbed shoreline of the island is of $2.20 \mathrm{~m}$. The island (radius at the tank bottom level $4.45 \mathrm{~m}$ ) has been built at the center of the tank using PVC sheets (thickness $0.01 \mathrm{~m}$ ) sustained by a steel frame (see Figs. 1 and 2). The plastic sheets are stiff enough to prevent any vibration induced by the landslide motion and by the waves. The slope of the flanks of the island is $1 / 3$ ( 1 vertical, 3 horizontal). Then the experimental configuration is characterized by a conical island placed in a constant water depth domain. It is important to note that if the island reproduced in the laboratory is scaled up of 1000 times using the Froude scaling law a prototype island similar to Stromboli is obtained.

The landslide model has a regular shape that reproduces a half of an ellipsoid (also used by Di Risio et al., 2009b) that, in a reference frame with the origin placed at the center of the ellipsoid, can be described by the equation $x^{2} / a^{2}+y^{2} / b^{2}+z^{2} / c^{2}=0$. Then the landslide width is equal to $0.40 \mathrm{~m}$ (axis $a$ parallel to the undisturbed shoreline equal to $0.20 \mathrm{~m}$ ), the landslide length to $0.80 \mathrm{~m}$ and the landslide 


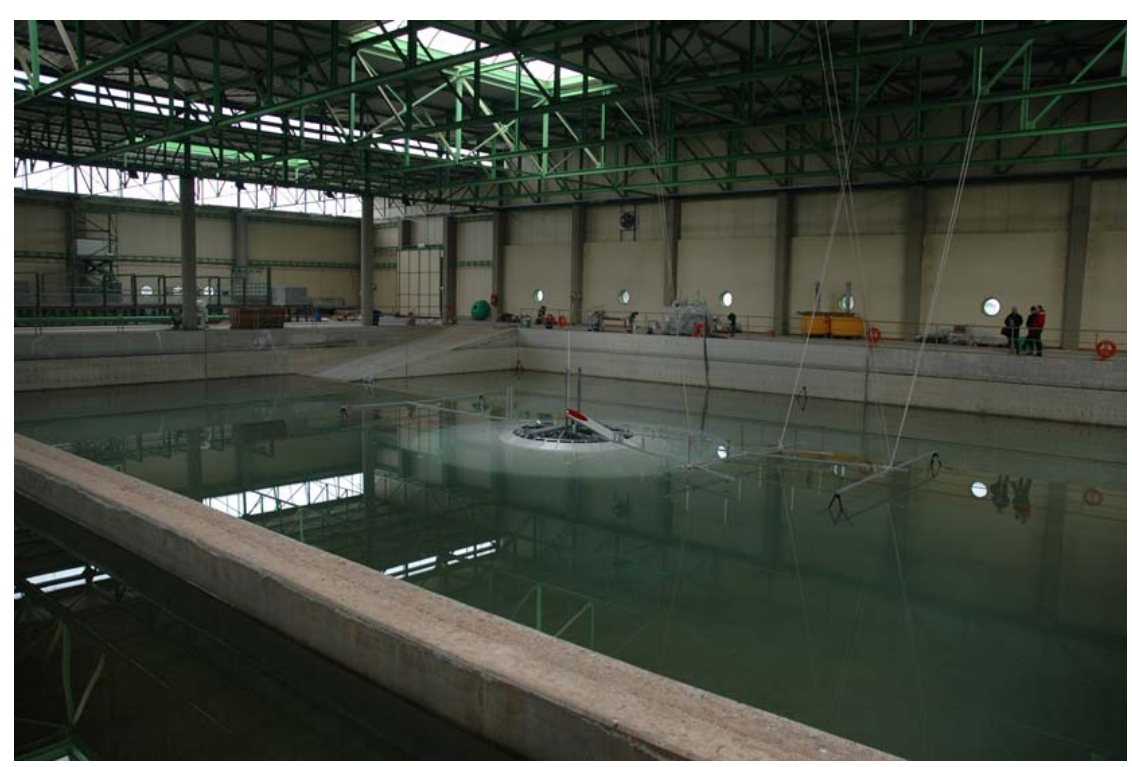

Fig. 1. View of conical island into the wave tank.

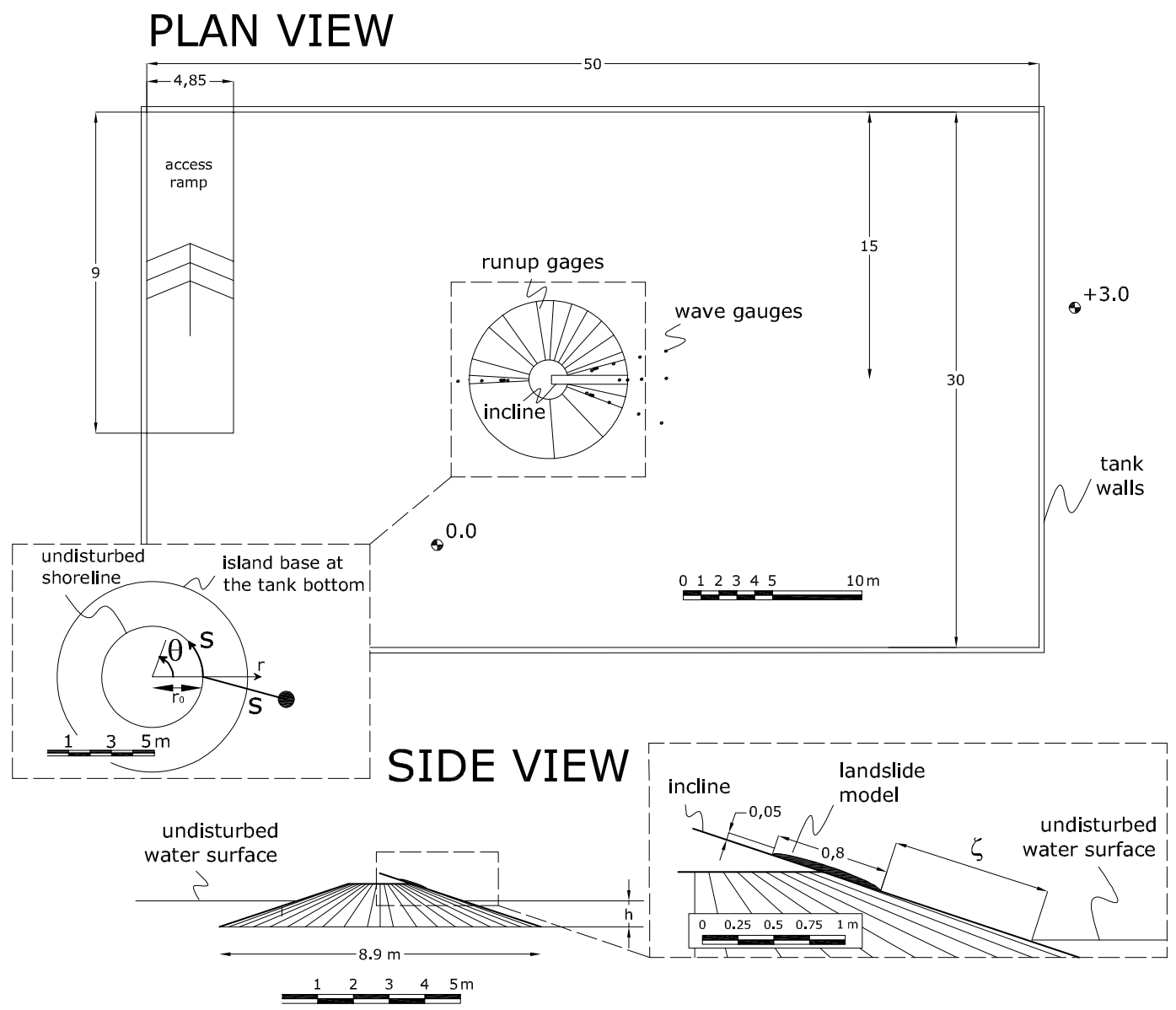

Fig. 2. Sketch of conical island and reference frame along with runup and wave gauges locations (length unit in meters). 
thickness to $0.05 \mathrm{~m}$ for a total volume $V=0.0084 \mathrm{~m}^{3}$. The density of the landslide is $1.83 \cdot 10^{3} \mathrm{~kg} / \mathrm{m}^{3}$ for a total mass of $15.40 \mathrm{~kg}$. The landslide is made up of plastic material covered by an exterior layer of fiberglass and the flat bottom, which is in contact with the flank of the island, is made up of steel. The landslide is constrained to move on rails placed along the slope and therefore it moves exactly along a specified axis. In order to reconstruct the landslide motion a capacitive accelerometer (Metra-Mess CB41) has been placed inside the landslide to measure its acceleration. For a description of landslide motion see Di Risio et al. (2009a) and Di Risio et al. (2009b). Here it is worth to mention that the impact velocity measured in the experiments ranged between 0.85 and $1.20 \mathrm{~m} / \mathrm{s}$. Scaling up to prototype this would correspond to a very fast landslide with impact velocity of the order of $30 \mathrm{~m} / \mathrm{s}$.

The instantaneous displacements of the shoreline have been measured by means of special wave gauges that have been built employing two steel bars (square section of $4 \mathrm{~mm} \times 4 \mathrm{~mm}$ ) directly embedded into the PVC of the slope. These instruments present higher noise and lower resolution $(0.55 \mathrm{~mm}$ and $0.50 \mathrm{~mm}$, respectively) than the traditional resistive gauges usually employed, but data still remain reliable. The surface elevation has been recorded using traditional resistive gauges. All the signals have been acquired simultaneously at a frequency of $1000 \mathrm{~Hz}$. It is to be noticed that surface elevation time series have not be presented in the paper of Di Risio et al. (2009a).

The reference coordinate system used in the subsequent analysis is in cylindrical coordinates and is presented in Fig. 2. The horizontal polar axes $r$ and $\theta$ respectively measure the distance from the plan center of the island and the angle, positive counterclockwise, between any line passing from the center of the island and the axis along which the landslide moves. A curvilinear abscissa $s$ is measured counterclockwise along the undisturbed shoreline starting from the point where the landslide enters the water $\left(r=r_{0}, \theta=0\right)$. For the offshore gauges $s$ represents the distance from the point where the landslide enters the water; this is used in order to compare the arrival times at the two systems of gauges by using the same parameter in order to measure the distance from the source.

Several tests have been performed by varying the height from which the landslide falls into the water which is measured, along the inclined plane, by the distance $\zeta$ between the low point of the landslide and the undisturbed shoreline (see Fig. 2). The release distance $\zeta$ assumed values of $+0.60 \mathrm{~m},+0.50 \mathrm{~m},+0.40 \mathrm{~m}$ and $+0.30 \mathrm{~m}$ : only subaerial landslides have been studied. Each test has been repeated twice in order to check for repeatability of the experiments.

In this paper the results obtained at all the run-up gauges and all the surface level gauges (depicted in Fig. 2 and summarised in Table 1) are used for the tests with $r_{0}=2.20 \mathrm{~m}$ and for all the values of $\zeta$.
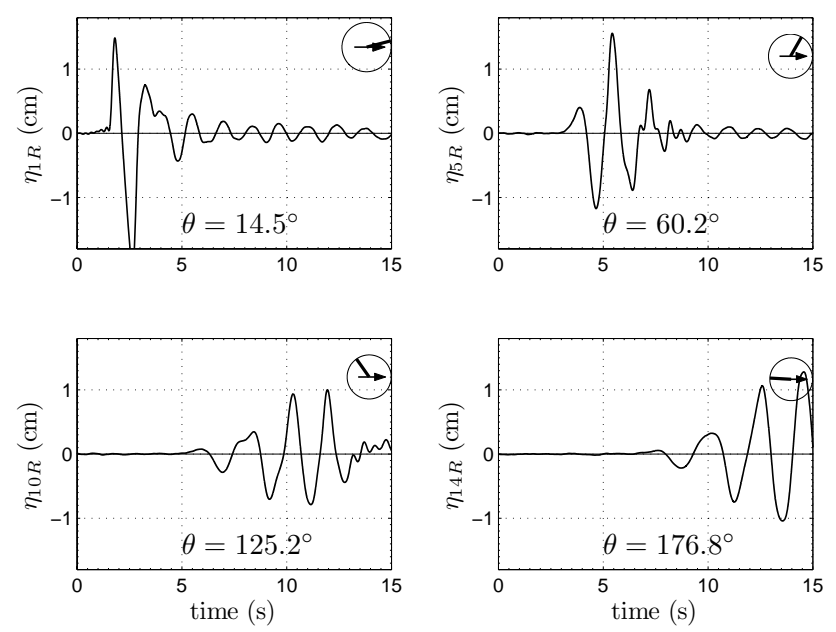

Fig. 3. Runup time series measured during experiments with $\zeta=+0.60 \mathrm{~m}$ and $r_{0}=2.20 \mathrm{~m}$. The small circle on each plot reproduces the coastline, the arrow indicates where the landslide enters the water, and the bold line specifies the position of the considered runup gauge (the island is oriented as in Fig. 2).

\section{Physical model results}

\subsection{Shoreline position records}

Sample records of the runup gauges for an experiment carried out using $\zeta=+0.60 \mathrm{~m}$ and $r_{0}=2.20 \mathrm{~m}$ (but very similar results have been obtained for different values of these parameters) are presented in Fig. 3. On each subplot the instantaneous vertical elevation of the shoreline position is reported; a small circle and a line are used on each plot to indicate the position of the runup gauge on the island flanks; the arrow indicates the direction of the landslide as it falls. During the experiments more runup gauges than those presented here were used, for a complete picture of the shoreline movements around the island refer to Di Risio et al. (2009a).

The analysis of the results reveals that the first generated wave always has first a crest followed by a trough. As a general behaviour the crest of the first wave tends to become smaller as it propagates around the island, while the trough remains quite large in comparison to the crest. The maximum inundation is given by the first wave crest in proximity of the landslide, then by the second wave crest as one moves away from the generation area, then by the third and so on. The maximum elevation of the shoreline does not travel in phase with the waves suggesting a dispersion mechanism that $\mathrm{Di}$ Risio et al. (2009a) address to be due to edge waves formation. The crest of the first wave becomes so small (in comparison with the following crests and troughs), that people along the coast may not detect it at all; more likely in the areas far from the source the first evidence of the tsunami attack is the withdrawal of the waters, i.e. the trough of the first wave. In the past it was believed that the above described inundation 
pattern was specific of submerged landslides tsunamis. The present experiments show that also subaerial landslides may induce a small-crest and large trough first wave, the first crest potentially so small to become not recognizable.

One first important point is therefore to be kept in mind: the tsunami that attacks the island is not a single wave, but a wave packet. The maximum inundation is not always given by the first wave, but it is likely to be induced by those that will follow the first, especially in the areas not very close to the source. Of course also the non highest waves can be destructive for the coast, so in the following we will consider two distinct parameters for describing the arrival times of the waves. These are the first wave front and the maximum shoreline elevation given by the wave packet.

The results strongly suggest that awareness of the people living in the areas prone to the risk of tsunami attack should be considered to be the first and probably the most efficient form of warning system. The withdrawal of the waters is a precursor of a tsunami inundation. Then, once the coast has been inundated it is likely that the following waves will give larger inundations. People that move away from the coast during the first wave attack and are not caught by the waters should keep moving away from the sea, since the following waves may be (and in the far field certainly they are) more devastating than the previous ones.

\subsection{Offshore surface level records}

Some of the offshore surface level records obtained during the same experiment considered above are reported in the Fig. 4. Also the waves that propagate offshore are wave packets, and the first wave is the highest only very close to the source. Two features of these waves appear worth to be pointed out for the present purposes. The first is that they appear to propagate faster than those around the island. The second point is that these waves are not very long in comparison to the water depth in the constant-depth area.

The first consideration immediately suggests that offshore gauges for the measurement of the generated tsunamis may be of great importance for TEWS. The waves that propagate offshore travel on areas of increasing water depths, and therefore tend to have increasing wave celerity. An offshore gauge placed at the same distance from the source of a coastal one will detect the tsunamis before the latter will. It is critical to asses what is the advantage in terms of time between these types of gauges; this will be addressed in the following section.

The second point is very important when considering the most appropriate strategy for theoretical/numerical modeling of the considered type of waves. It is well known that tsunamis generated by landslides are much shorter than those induced by earthquakes; Lynett and Liu (2005) and Watts et al. (2003) in view of this have developed numerical models able to deal with relatively long waves considering the frequency dispersion effect to some extent. But the present
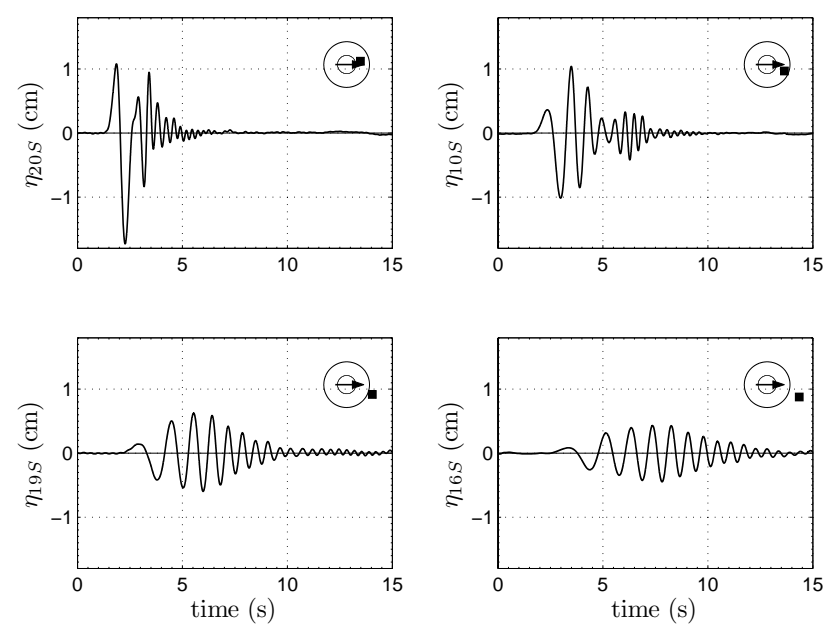

Fig. 4. Surface level time series measured during experiments with $\zeta=+0.60 \mathrm{~m}$ and $r_{0}=2.20 \mathrm{~m}$. The small circles on each plot reproduces the coastline and the island base on the tank bottom, the arrow indicates where the landslide enters the water, and the square marker the position of the considered gauge (the island is oriented as in Figure 2).
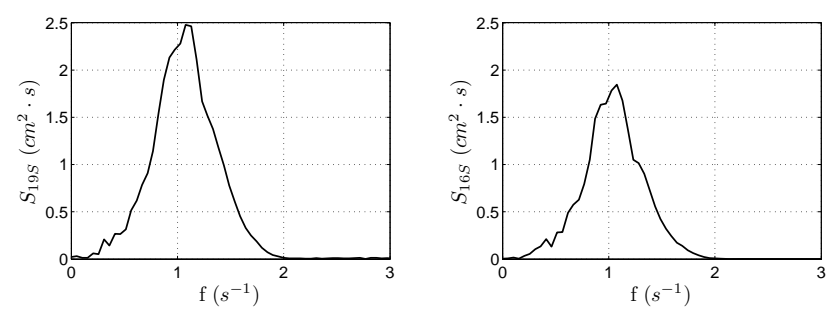

Fig. 5. Power spectrum of surface level time series for gauges $19 \mathrm{~S}$ (left panel, $r=5.42 \mathrm{~m}, \theta=20.9^{\circ}, s=3.45 \mathrm{~m}$ ) and $16 \mathrm{~S}$ (right panel, $r=6.78 \mathrm{~m}, \theta=21.0^{\circ}, s=4.80 \mathrm{~m}$ ), for the experiment with $\zeta=+0.60 \mathrm{~m}$.

results seem to indicate that the waves are more deep-water waves than long ones. Spectral analysis of the surface level records shows that the peak frequency of the wave packet is of the order of $1 \mathrm{~s}$ (about $30 \mathrm{~s}$ in prototype scale, Fig. 5). On a water depth of $0.75 \mathrm{~m}$ (750 $\mathrm{m}$ in prototype scale) this corresponds to a peak wave length of $1.55 \mathrm{~m}(1550 \mathrm{~m}$ in prototype scale), i.e. approximately two times the water depth. In conclusion a large portion of the wave packet energy pertains to deep water waves. This is true already at $2.25 \mathrm{~m}(2250 \mathrm{~m}$ in prototype scale) from the coast. If offshore gauges are employed to obtain information on the waves that are attacking the coast, the frequency dispersion effects should be taken into account with great care: traditional numerical models based on the long waves approximation or on weakly frequency dispersive equations, may be not adequate for this purpose. It is however to be kept in mind that the properties of the waves are expected to depend on the landslide 


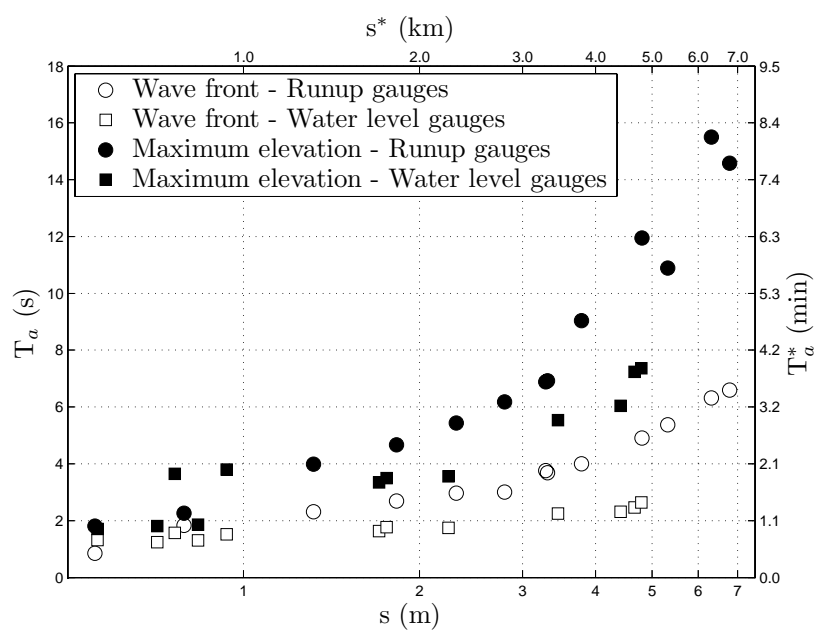

Fig. 6. Arrival time $T_{a}$ of maximum elevation (dark markers) and of wave front (empty markers) propagating along the coastline (circles) and offshore (squares) as a function of travel path $s$. Bottom and left axis refer to experimental dimensions $\left(T_{a}\right.$ and $\left.s\right)$, top and right axis refer to prototype dimensions $\left(T_{a}^{*}\right.$ and $\left.s^{*}\right)$. The data refer to the experiment with $\zeta=+0.60 \mathrm{~m}$.

shape and kinematics. More specifically larger landslides would generate longer waves that should be less dispersive than those recorded in these experiments.

\subsection{Propagation times: coastal and offshore gauges}

In this section we analyze the time taken by the waves to propagate around the island. We focus on the arrival time of the first wave and of the wave that gives the maximum inundation. The arrival time of the first wave (in the following also referred to as the arrival of the tsunami and indicated by $t_{a}$ ) is calculated by seeking in the data for the time at which the surface elevation exceeds a fixed threshold. The arrival time of the maximum inundation is the time at which the largest surface elevation is recorded by the gauges and in the following is indicated by $t_{m}$.

The results are presented in the Fig. 6 for the experiment with $\zeta=+0.60 \mathrm{~m}$ and in the Table 1 also for those with $\zeta=+0.50,+0.40,+0.30 \mathrm{~m}$. The logarithmic $\mathrm{x}$-axis of the figure indicates the distance of each measurement point from the point at which the landslide impacts the water. For the coastal gauges this distance is measured counterclockwise along the coast of the island; for the offshore gauges it is the distance from the point at which the landslide hits the water. It is to be remembered that the island coastline is a circle and that half of its circumference is $6.91 \mathrm{~m}$; the figure therefore shows results for about one half of the island. The primary $\mathrm{y}$-axis is the elapsed time since the landslide hits the water; the secondary $y$-axis gives the elapsed time at an ideal prototype scale, by assuming the present experiment to reproduce a real case scaled down of 1000 times using the Froude scaling law. This is obtained by multiplying the laboratory times by $\sqrt{1000}$. The shape of each marker indicates whether the measure refers to runup gauges (circles) or offshore gauges (squares).

In the very near field, i.e. for $s<1 \mathrm{~m}$, the results appear to be quite confusing, and no clear tendency in the data can be appreciated. On the contrary in the far field it is clear that the wave front is detected firstly at the offshore gauges and then at the runup ones. The time lag between the detection of the arrival of the waves between the two set of gauges is of the order of $1 s$ (about $30 s$ in prototype scale) and increases with $s$, considering gauges with the same distance from the source.

A further point of interest is that along the coastal gauges the wave front arrives very early respect to the maximum inundation. For instance for the experiment with $\zeta=+0.60 \mathrm{~m}$ at $s=1.32 \mathrm{~m}\left(\theta=+34.3^{\circ}\right)$ the wave front precedes the maximum elevation of $1.67 \mathrm{~s}$, which at an ideal prototype scale corresponds to about 1 minute. At $s=3.79 \mathrm{~m}\left(\theta=98.7^{\circ}\right)$ the difference grows up to $5.04 \mathrm{~s}$ (more than 2 and a half minutes in prototype) and tends to grow further as $s$ increases. It is to be noted that there is no appreciable difference between the data referring to experiments with values of $\zeta$ between +0.60 and $+0.30 \mathrm{~m}$.

The arrival times presented in this section, once scaled up to match the actual dimensions of the prototype case of interest, are in our opinion of great value for the design and the optimization of a TEWS. Once the position of the wave gauges has tentatively been decided, and by knowing the locations along the coast to be protected (town, villages, etc.), it is easy to calculate the time elapsed from the measurement and the arrival of the tsunami and of the largest wave crest.

\subsection{Example of a TEWS}

In order to show how one can use the data, let us now imagine that the TEWS is aimed at protecting a point along the island coast located at approximately $\theta=90^{\circ}$ (point of interest, POI in Fig. 7) and that use is made of a coastal gauge (nearshore gauge, NS in Fig. 7) located approximately at $\theta=45^{\circ}$ and of an offshore gauge (OS in Fig. 7).

Using the experimental time series collected by means of runup gauge 4R (close to NS), 7R (POI) and of surface elevation gauge $20 \mathrm{~S}$ (OS) for $\zeta=+0.60 \mathrm{~m}$, it is possible to study how the TEWS would work. The gauges positions do not coincide exactly with those of the points to be considered and in the practice more precise results may be obtained by interpolating the data between neighbor gauges; however for the present purposes it suffices to use available measurement points.

The tsunami wave front is firstly detected at OS location (indicated as 1 in OS time series) and the first alarm is spread; we will use this instant to establish a TEWS time $t_{\mathrm{TEWS}}=0.00 \mathrm{~s}$. Then the wave measured at OS location 
Table 1. Sensors position and arrival times of the waves for the experiments with $\zeta=+0.60,+0.50,+0.40,+0.30 \mathrm{~m}$ shown in Fig. 6 .

\begin{tabular}{|c|c|c|c|c|c|c|c|c|c|c|c|}
\hline \multirow[b]{2}{*}{$\begin{array}{l}\text { Sensor } \\
\text { name }\end{array}$} & \multirow[b]{2}{*}{$\begin{array}{c}r \\
(\mathrm{~m})\end{array}$} & \multirow[b]{2}{*}{$\begin{array}{c}\theta \\
\left(^{\circ}\right)\end{array}$} & \multirow[b]{2}{*}{$\begin{array}{c}s \\
(\mathrm{~m})\end{array}$} & \multicolumn{2}{|c|}{$\zeta=+0.60 \mathrm{~m}$} & \multicolumn{2}{|c|}{$\zeta=+0.50 \mathrm{~m}$} & \multicolumn{2}{|c|}{$\zeta=+0.40 \mathrm{~m}$} & \multicolumn{2}{|c|}{$\zeta=+0.30 \mathrm{~m}$} \\
\hline & & & & $\begin{array}{l}t_{a} \\
(\mathrm{~s})\end{array}$ & $\begin{array}{l}t_{m} \\
(\mathrm{~s})\end{array}$ & $\begin{array}{l}t_{a} \\
(\mathrm{~s})\end{array}$ & $\begin{array}{l}t_{m} \\
(\mathrm{~s})\end{array}$ & $\begin{array}{l}t_{a} \\
(\mathrm{~s})\end{array}$ & $\begin{array}{l}t_{m} \\
(\mathrm{~s})\end{array}$ & $\begin{array}{l}t_{a} \\
(\mathrm{~s})\end{array}$ & $\begin{array}{l}t_{m} \\
(\mathrm{~s})\end{array}$ \\
\hline \multicolumn{12}{|c|}{ Runup gauges } \\
\hline $1 \mathrm{R}$ & 2.2 & 14.5 & 0.56 & 0.847 & 1.806 & 0.896 & 1.812 & 0.882 & 1.798 & 0.812 & 1.736 \\
\hline $2 \mathrm{R}$ & 2.2 & 20.6 & 0.80 & 1.837 & 2.255 & 1.804 & 2.251 & 1.749 & 2.230 & 1.730 & 2.174 \\
\hline $3 R$ & 2.2 & 34.3 & 1.32 & 2.316 & 3.986 & 2.275 & 4.067 & 2.016 & 4.166 & 2.137 & 4.064 \\
\hline $4 \mathrm{R}$ & 2.2 & 47.6 & 1.83 & 2.687 & 4.673 & 2.664 & 4.728 & 2.482 & 4.764 & 2.638 & 4.680 \\
\hline $5 \mathrm{R}$ & 2.2 & 60.2 & 2.31 & 2.971 & 5.434 & 2.904 & 5.447 & 2.713 & 5.461 & 2.953 & 5.390 \\
\hline $6 \mathrm{R}$ & 2.2 & 72.9 & 2.80 & 3.002 & 6.183 & 3.453 & 6.172 & 3.254 & 6.175 & 3.430 & 6.115 \\
\hline $16 \mathrm{R}$ & 2.2 & 85.7 & 3.30 & 3.761 & 6.882 & 3.854 & 6.888 & 3.986 & 6.889 & 3.849 & 6.834 \\
\hline $7 \mathrm{R}$ & 2.2 & 86.3 & 3.31 & 3.679 & 6.926 & 3.827 & 6.942 & 3.897 & 6.920 & 3.690 & 6.877 \\
\hline $8 \mathrm{R}$ & 2.2 & 98.7 & 3.79 & 3.998 & 9.037 & 4.152 & 9.032 & 4.123 & 9.011 & 4.221 & 8.967 \\
\hline $10 \mathrm{R}$ & 2.2 & 125.2 & 4.81 & 4.905 & 11.946 & 4.856 & 11.967 & 4.490 & 10.348 & 4.891 & 10.300 \\
\hline $11 \mathrm{R}$ & 2.2 & 138.6 & 5.32 & 5.377 & 10.886 & 5.546 & 10.916 & 4.363 & 10.927 & 5.365 & 10.876 \\
\hline $13 R$ & 2.2 & 164.6 & 6.32 & 6.320 & 15.497 & 6.262 & 15.482 & 6.182 & 15.479 & 6.419 & 15.427 \\
\hline $14 \mathrm{R}$ & 2.2 & 176.8 & 6.79 & 6.598 & 14.574 & 6.624 & 14.597 & 6.301 & 14.577 & 6.673 & 14.522 \\
\hline \multicolumn{12}{|c|}{ Water level gauges } \\
\hline $12 \mathrm{~S}$ & 2.49 & 11.8 & 0.56 & 1.317 & 1.711 & 1.323 & 1.714 & 1.304 & 1.697 & 1.246 & 1.624 \\
\hline $25 \mathrm{~S}$ & 2.65 & 13.2 & 0.71 & 1.239 & 1.805 & 1.281 & 1.824 & 1.279 & 1.813 & 1.233 & 1.745 \\
\hline $11 \mathrm{~S}$ & 2.27 & 19.5 & 0.76 & 1.564 & 3.645 & 1.553 & 3.703 & 1.573 & 3.713 & 1.493 & 3.661 \\
\hline $20 \mathrm{~S}$ & 2.80 & 13.5 & 0.83 & 1.307 & 1.858 & 1.338 & 1.882 & 1.324 & 1.874 & 1.261 & 1.810 \\
\hline $18 \mathrm{~S}$ & 2.63 & 19.9 & 0.94 & 1.513 & 3.801 & 1.523 & 3.863 & 1.544 & 3.877 & 1.471 & 3.825 \\
\hline $7 \mathrm{~S}$ & 3.76 & 13.7 & 1.71 & 1.626 & 3.341 & 1.678 & 3.388 & 1.542 & 3.395 & 1.671 & 3.348 \\
\hline $10 \mathrm{~S}$ & 3.64 & 20.5 & 1.76 & 1.768 & 3.495 & 1.613 & 3.534 & 1.715 & 3.540 & 1.774 & 3.486 \\
\hline $15 \mathrm{~S}$ & 4.44 & 0.1 & 2.24 & 1.745 & 3.563 & 1.735 & 3.623 & 1.731 & 3.649 & 1.745 & 3.606 \\
\hline $19 \mathrm{~S}$ & 5.42 & 20.9 & 3.45 & 2.247 & 5.536 & 2.190 & 5.587 & 2.120 & 5.606 & 2.241 & 5.554 \\
\hline $24 \mathrm{~S}$ & 6.62 & 0.6 & 4.42 & 2.315 & 6.038 & 2.376 & 6.097 & 2.294 & 6.115 & 2.315 & 6.070 \\
\hline $16 \mathrm{~S}$ & 6.78 & 21.0 & 4.80 & 2.635 & 7.364 & 2.561 & 8.310 & 2.444 & 7.436 & 2.347 & 8.264 \\
\hline
\end{tabular}

reaches its maximum value (labeled as 2 in OS time series) and the order of magnitude of the waves is already available (i.e. $t_{\mathrm{TEWS}}=0.59 \mathrm{~s}$ ). Then the tsunami wave front reaches the NS location $\left(t_{\mathrm{TEWS}}=1.38 \mathrm{~s}\right)$ and the POI location $\left(t_{\text {TEWS }}=2.20 \mathrm{~s}\right)$. The maximum inundation occurs at $t_{\text {TEWS }}=3.40 \mathrm{~s}$ at the NS location and at $t_{\text {TEWS }}=5.65 \mathrm{~s}$ at the POI location.

Since the tsunami is detected at the OS, it takes $2.20 s$ for the tsunami to attack the POI. Using the NS the time available between the detection and the arrival is just $0.82 s$; scaling these times to prototype (scale 1:1000) they are equal respectively to $70 s$ and $26 s$. However, it is to be considered that at the POI the first wave has a very small crest, a large trough and then a very large crest that gives the maximum inundation. The maximum inundation takes place at the POI after $5.65 s$ (179s at prototype) the tsunami has been detected at OS and $4.27 s$ (135s at prototype) after detection at NS. It follows that the alarm may be spread about two minutes before the coast is inundated. As far as the estimation of the inundation level is concerned the maximum runup is recorded at the POI $5.06 s(160 s)$ after it takes place at the
OS and $2.25 s(71 s)$ after it is recorded at the NS. An estimation of the safe distance from the coast can therefore be spread more than one minute (at prototype scale) before the inundation occurs.

\section{Conclusions}

In this paper we have used the results of an experimental research to investigate how a TEWS aiming at alarming an island coast would work in the case of tsunamis generated by landslides falling along the coast of the island itself. We have provided with data about the propagation times of the tsunami around the island that, once scaled at the appropriate prototype scale, may be used to design and optimize a TEWS.

One of the conclusions is that the time available for detecting the tsunamis and spreading the alarm is of the order of few minutes. However the fact that the waves propagating along the coast are dispersive, i.e. the maximum inundation does not travel in phase with the waves, leaves much more 

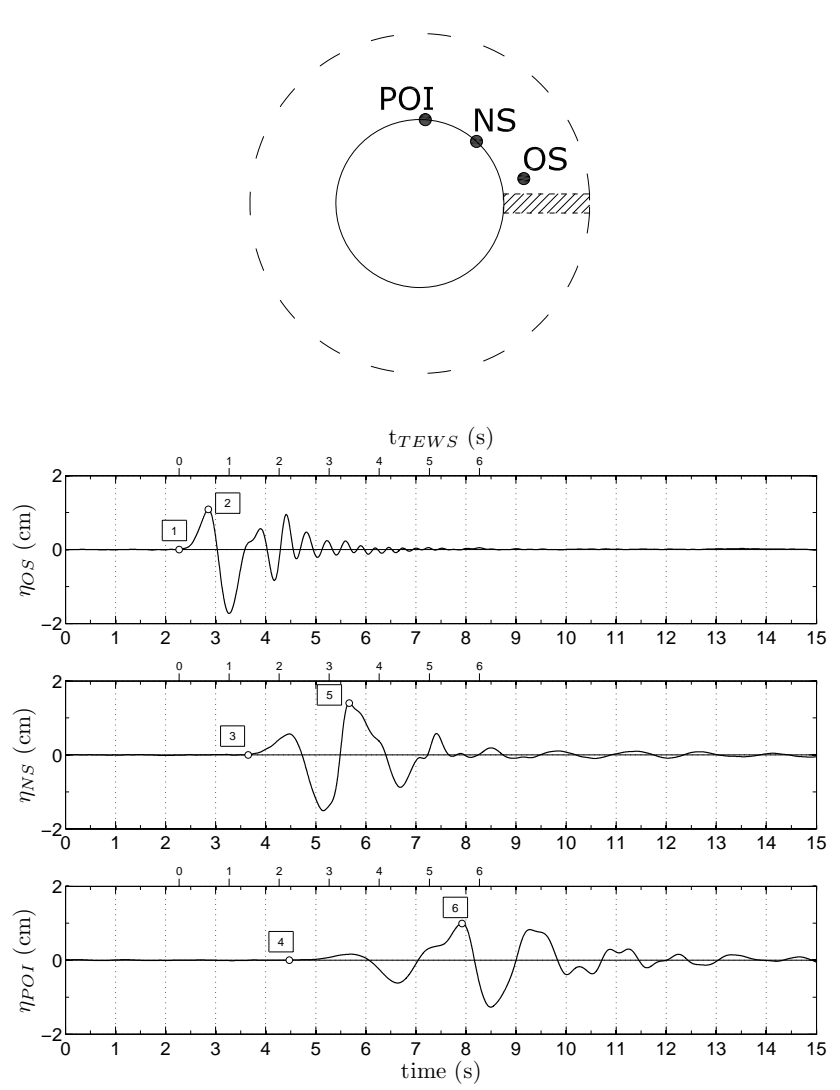

Fig. 7. Sketch of the considered TEWS along with time series measured at the offshore sensor OS (upper panel), the nearshore sensor NS (middle panel) and at the point of interest POI (lower panel). Squared numbers refer to the instant at which the wave front reaches OS (1), NS (3) and POI (4) and when maximum tsunami amplitudes occur at OS (2), NS (5) and POI (6).

time than one would imagine. More specifically the maximum inundation takes place much later than the first tsunami attack. It is important to stress once again that awareness of the people living along the coast is of the utmost importance, since the first waves are (especially in the very far field) not those giving the largest inundation.

Finally there is a further question to be answered when designing a TEWS: is it better to use coastal or offshore wave measurement devices? Both have points of strength and weakness. Coastal wave gauges are the most obvious way of measuring tsunamis propagating along the coast. However, as shown in this paper, the tsunamis tend to propagate slowly around the coast, if compared to the waves propagating offshore; this results in reduced times for spreading the alarm when use is made of coastal gauges. The waves propagate faster toward offshore than along the coast, so that the system based on offshore gauges is expected to have more time for spreading the alarm. However in this paper we have shown that the waves propagating offshore are almost deep water waves at a very small distance from the island. This implies that pressure disturbances induced at the bottom are very small and hardly detectable using standard pressure sensors.

This paper shows that both off- and near-shore sensors can be used together to build an efficient TEWS. In the case of an idealized conical island with a undisturbed shoreline radius of about $2.2 \mathrm{~km}$, and a sea depth of about $750 \mathrm{~m}$, it can spread the alarm about 2 min before the tsunami reaches its maximum elevation at a point located at $\theta=90^{\circ}$ with respect to the axis along which the landslide slides down the flank of the island. Furthermore, more than a $1 \mathrm{~min}$ before the maximum inundation occurs, the TEWS can give an estimation of the safe distance from the coast, i.e. level of induced runup. How much the results obtained in the experiments generalize to real life cases like for example the Stromboli island tsunamis, is not very clear up to now. The results however can certainly give an order of magnitude of the arrival times for many volcanic islands; it is one of our future research lines to check the differences between what would happen for a simplified shape island and a real one.

It is finally worth to remind that waves generated by landslides along a coast may be destructive also for coastal regions far from the island. A warning system should therefore be able to predict to what distance from the source the alarm should be spread. This part of the problem has not been described in the present paper.

Acknowledgements. This work was carried out under the research project PRIN2007 ("Development and validation of hydraulic and geologic tools for supporting a Tsunami Early Warning System. Implementation to the Stromboli (Eolie) landslide case.”) funded by the Italian Ministry for University and Scientific Research (MIUR). Authors whish to thank Matteo G. Molfetta and Luigi Pratola for their help during the experimental investigation and Antonio F. Petrillo for the useful discussions. The Authors finally thank the technicians of the LIAM laboratory (University of L'Aquila) Mario Nardi and Lucio Matergia who built the conical island.

Edited by: S. Tinti

Reviewed by: C. B. Harbitz and another anonymous referee

\section{References}

Bellotti, G., Cecioni, C., and De Girolamo, P.: Simulation of small-amplitude frequency-dispersive transient waves by means of the mild-slope equation, Coast. Eng., 55(6), 447-458, doi:10.1016/j.coastaleng.2007.12.006, 2008.

Beltrami, G. M.: An ANN algorithm for automatic, real-time tsunami detection in deep-sea level measurements, Ocean Eng., 35(5-6), 572-587, doi:10.1016/j.oceaneng.2007.11.009, 2008.

Beltrami, G. M. and Di Risio, M.: Algorithms for real-time tsunami detection in wind-wave measurements, Abstract submitted to XXXII International Conference on Coast. Eng.-ICCE, 2009. 
Casagli, N., Tibaldi, A., Merri, A., Del Ventisette, C., Apuani, T., Guerri, L., Fortuny-Guasch, J., and Tarchi, D.: Deformation of Stromboli Volcano (Italy) during the 2007 eruption revealed by radar interferometry, numerical modelling and structural geological field data, J. Volcanol. Geoth. Res., 182(3-4), 182-200, doi:10.1016/j.jvolgeores.2009.01.002, 2009.

Di Risio, M., De Girolamo, P., Bellotti, G., Panizzo, A., Aristodemo, F., Molfetta, M. G., and Petrillo, A. F.: Landslidegenerated tsunamis runup at the coast of a conical island: new physicalmodel experiments, J. Geophys. Res., 114, C01009, doi:10.1029/2008JC004858, 2009a.

Di Risio, M., Bellotti, G., Panizzo, A., and De Girolamo, P.: Three-dimensional experiments on landslide generated waves at a sloping coast, Coast. Eng., 56(5-6), 659-671 doi:10.1016/j.coastaleng.2009.01.009, 2009b.

Lynett, P. and Liu, P. L.-F.: A numerical study of the runup generated by threedimensional landslides, J. Geophys. Res.-Oceans, 110(C3), C03006, doi:10.1029/2004JC002443, 2005.

Maramai, A., Graziani, L., and Tinti, S.: Tsunamis in the Aeolian Islands (southern Italy): a review, Mar. Geol., 215(1-2), 11-21, doi:10.1016/j.margeo.2004.03.018, 2005.

Tibaldi, A.: Multiple sector collapses at Stromboli volcano, Italy: How they work, B. Volcanol., 63, 112-125, 2001.
Tinti, S., Pagnoni, G., Zaniboni, F., and Bortolucci, E.: Tsunami generation in Stromboli island and impact on the south-east Tyrrhenian coasts, Nat. Hazards Earth Syst. Sci., 3, 299-309, 2003, http://www.nat-hazards-earth-syst-sci.net/3/299/2003/.

Tinti, S., Manucci, A., Pagnoni, G., Armigliato, A., and Zaniboni, F.: The 30 December 2002 landslide-induced tsunamis in Stromboli: sequence of the events reconstructed from the eyewitness accounts, Nat. Hazards Earth Syst. Sci., 5, 763-775, 2005, http://www.nat-hazards-earth-syst-sci.net/5/763/2005/.

Tinti, S., Pagnoni, G., and Zaniboni, F.: The landslides and tsunamis of the 30th of December 2002 in Stromboli analysed through numerical simulations, B. Volcanol., 68(5), 462-479, doi:10.1007/s00445-005-0022-9, 2006.

Tinti, S., Zaniboni, F., Pagnoni, G., and Manucci, A.: Stromboli Island (Italy): Scenarios of Tsunamis Generated by Submarine Landslides, Pure Appl. Geophys., 165(11-12), 2143-2167, doi: 10.1007/s00024-008-0420-y, 2008.

Watts, P., Grilli, S. T., Kirby, J. T., Fryer, G. J., and Tappin, D. R.: Landslide tsunami case studies using a Boussinesq model and a fully nonlinear tsunami generation model, Nat. Hazards Earth Syst. Sci., 3, 391-402, 2003, http://www.nat-hazards-earth-syst-sci.net/3/391/2003/. 